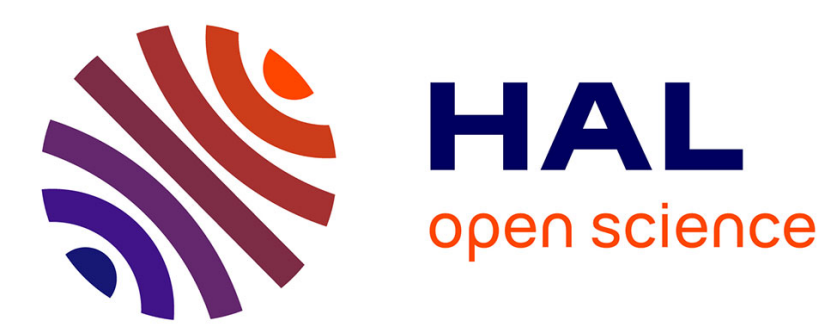

\title{
Track-etched nanopores in spin-coated polycarbonate films applied as sputtering mask
}

Anne-Katrin Nix, H.-G. Gehrke, J. Krauser, C. Trautmann, A. Weidinger, H. Hofsäss

\section{- To cite this version:}

Anne-Katrin Nix, H.-G. Gehrke, J. Krauser, C. Trautmann, A. Weidinger, et al.. Track-etched nanopores in spin-coated polycarbonate films applied as sputtering mask. The Seventh International Symposium on Swift Heavy Ions in Matter, Jun 2008, Lyon, France. hal-00249369

\section{HAL Id: hal-00249369 \\ https://hal.science/hal-00249369}

Submitted on 25 Jul 2008

HAL is a multi-disciplinary open access archive for the deposit and dissemination of scientific research documents, whether they are published or not. The documents may come from teaching and research institutions in France or abroad, or from public or private research centers.
L'archive ouverte pluridisciplinaire HAL, est destinée au dépôt et à la diffusion de documents scientifiques de niveau recherche, publiés ou non, émanant des établissements d'enseignement et de recherche français ou étrangers, des laboratoires publics ou privés. 


\title{
Track-etched nanopores in spin-coated polycarbonate films applied as
}

\section{sputtering mask}

\author{
A.-K. Nix ${ }^{1}$, H.-G. Gehrke ${ }^{1}$, J. Krauser ${ }^{2}$, C. Trautmann ${ }^{3}$, A. Weidinger ${ }^{4}$, H. Hofsäss ${ }^{1}$ \\ ${ }^{1}$ II. Physikalisches Institut, Universität Göttingen, Germany; ${ }^{2}$ Hochschule Harz, \\ Wernigerode, Germany; ${ }^{3}$ Gesellschaft für Schwerionenforschung (GSI), Darmstadt, Germany \\ ${ }^{4}$ Hahn-Meitner-Institut, Berlin, Germany
}

\section{$\underline{\text { Abstract }}$}

Thin polycarbonate films were spin-coated on silicon substrates and subsequently irradiated with $1-\mathrm{GeV}$ U ions. The ion tracks in the polymer layer were chemically etched yielding nanopores of about $40 \mathrm{~nm}$ diameter. In a second process, the nanoporous polymer film acted as mask for structuring the Si substrate underneath. Sputtering with 5-keV Xe ions produced surface craters of depth $\sim 150 \mathrm{~nm}$ and diameter $\sim 70 \mathrm{~nm}$. This arrangement can be used for the fabrication of track-based nanostructures with self-aligned apertures.

PACS: 61.80.Jh; 61.82Pv

Keywords: polycarbonate, ion track, etching, sputtering, swift heavy ion irradiation 


\section{Introduction}

The irradiation of polymers with swift heavy ions of MeV-GeV kinetic energy leads to the creation of cylindrical zones of strongly modified material formed along the ion trajectories.

Such ion tracks have a typical diameter of a few nanometers whereas their length is adjustable by the beam energy and can reach several tens of micrometers or more. By far the most frequent application of ion tracks in polymers is linked to chemical etching which is based on the preferential dissolution of the damaged track material. In an appropriate chemical solution, the etch rate along the ion track can be orders of magnitude larger than the bulk etch rate of the surrounding matrix material [1]. Depending on the etching conditions (temperature, concentration, etching time, etc), the resulting pores have a size between a few tens nm and $\mu \mathrm{m}$. Track-etched pores are also characterized by an extremely uniform size and shape. In many applications polymer films are either directly perforating or material is deposited into the track-etched pores [2-4]. The replication benefits from the same advantages as the template itself, i.e., adjustable areal density, pore monodispersity, shape tuning, excellent control of diameter and length, and thus access to a wide range of aspect ratios. Nanowires of many different materials have been fabricated in track-etched membranes including e.g., copper [5], gold [6], or even ferromagnetic multilayers (e.g. copper-cobalt [7]). The objective of this project is to prepare electrical contacts for individual conducting ion tracks in a diamond-like carbon and - based on a similar approach - the fabrication of selfaligned field emission devices. The basic idea is schematically illustrated in Fig. 1. In both cases, etched ion tracks in a thin polymer film play a key role. The substrate is either a diamond-like carbon layer (Fig. 1a) or a more complex multilayer system. The diamond-like carbon layer (tetrahedral amorphous carbon (ta-C)) is insulating, but when irradiated with energetic heavy ions, conductive trails of less than $10 \mathrm{~nm}$ in diameter are formed [8-10]. Irradiating ta-C substrates or multi-layer systems with a thin polymer film on top with heavy ions leads to etchable tracks in the polymer self-aligned to the conductive tracks in the ta-C 
substrate underneath (Fig. 1a). For crystalline $\mathrm{Si}$ and $\mathrm{Cr}$ a direct structuring with swift heavy ions is not possible, because both materials are insensitive to ions in the electronic energy loss regime.

In a first step, the tracks in the polymer are developed into pores, which are subsequently filled with a metal either by thermal evaporation, sputter deposition, or electrodeposition. The metal-filling acts as electrical contact to the conducting track in the ta-C layer (Fig. 1a). Alternatively, the etched polymer pores serve as self-aligned apertures to access the multilayer system consisting of the ta-C substrate with an insulator and a metallic layer on top (Fig. 1b, polymer layer not shown). In this application, the tracks in the ta-C layer act as field emitters [11], and the insulating film together with the metal layer form the gate electrode. The aperture in the polymer represents a mask through which the insulator and the metal are locally removed e.g. by sputtering with a low-energy ion beam.

This work focuses on the etching process of ion tracks produced in a thin polycarbonate film deposited on a substrate. As polymer, we selected polycarbonate because its track-etching properties are well known $[12,13]$. Instead of a multilayered substrate, we tested track etching of a polycarbonate film spin-coated on silicon.

\section{Experimental}

The samples consisted of small pieces of highly conductive n-type Si wafers covered with polycarbonate by spin coating. Before film deposition, the native oxide layer of silicon was removed by immersing the samples for about $30 \mathrm{~s}$ in hydrofluoric acid (10\%). For spincoating, 3.2 g polycarbonate $\left(100-\mu \mathrm{m}\right.$ thick Makrofol- $\mathrm{N}^{\circledR}$ foil, Bayer) was dissolved in $80 \mathrm{ml}$ dichloromethane. The resist was dropped on the silicon substrate rotating with $1250 \mathrm{rpm}$ leading to a $600 \pm 50 \mathrm{~nm}$ thick film. The layer thickness was measured by means of profilometry (Dektak ${ }^{3} \mathrm{ST}$ surface profiler). All samples were examined with an optical microscope to exclude incomplete coverage and inclusions or dust particles. 
The irradiation experiments were performed at the linear accelerator UNILAC at GSI (Darmstadt) with $\mathrm{U}$ ions of $1 \mathrm{GeV}$ kinetic energy. The fluence was in the range of $5 \times 10^{8}$ to $5 \times 10^{9}$ ions $/ \mathrm{cm}^{2}$, which is sufficiently low to avoid significant pore overlapping after track etching. Earlier test experiments have shown that exceeding a fluence of about $10^{10}$ ions $/ \mathrm{cm}^{2}$ leads to a visible decomposition of the polymer film. The incident beam was perpendicular to the sample surface. When reaching the sample surface, the ions were at their equilibrium charge state adjusted by an aluminum degrader foil $\left(0.01269 \mathrm{~g} / \mathrm{cm}^{2}\right)$ mounted in front of the sample. The projected ion range was close to $100 \mu \mathrm{m}$, i.e., the projectiles completely penetrated through the polycarbonate layer.

After irradiation, the tracks in the polycarbonate film were etched in aqueous sodium hydroxide (5 mol/l) at room temperature (RT) using a typical etching time of about one hour. The etching results were controlled by means of scanning electron microscopy (SEM). To increase the contrast and avoid charging during SEM analysis, the samples were sputtercoated with a thin gold layer of about $7 \mathrm{~nm}$.

After track etching, a selected part of the sample surface was exposed to a beam of 5-keV Xeions in order to locally remove Si by sputtering, using the nanopores in the polymer film as mask. The process was performed at RT and under normal beam incidence applying a fluence of $10^{17}$ and $10^{18} \mathrm{Xe}$-ions $/ \mathrm{cm}^{2}$. To avoid sample heating, the beam current density was limited to $2 \sim 3 \mu \mathrm{A} / \mathrm{cm}^{2}$. After sputtering, the residual polycarbonate layer was removed with dichloromethane and the subjacent silicon was examined with SEM and atomic force microscopy (AFM) in contact mode.

\section{$\underline{\text { Results and Discussion }}$}

Track-etching produced nanopores in the polycarbonate layer (Fig. 2a) with a pore density which corresponds roughly to the irradiation fluence. The pore diameter (inner black contrast) scatters from 20 to about $50 \mathrm{~nm}$ with a mean value of $36 \pm 8 \mathrm{~nm}$ (the real size is probably 
slightly larger due to the sputtered gold layer). Assuming that the film thickness is not influenced by the etching procedure, the length-to-diameter ratio of the pores is $600 \mathrm{~nm} / 36 \mathrm{~nm}$ $\approx 17$. We confirmed that the pores were completely etched through the entire polymer layer by peeling off the film from the Si substrate (Fig. 2b). On the rear side of the film, the pores seem to be larger and exhibit a much broader size distribution. Details could not be analyzed, because the film was stressed and strongly deformed during the stripping procedure. The very large holes of irregular shape result from overlapping of neighboring pores. It also should be noted that the uncovered silicon surface did not reveal any etching-induced ion-track effects, as expected.

The result obtained after the sputtering process with $5-\mathrm{keV}$ Xe ions is reported in Fig. 3 showing an AFM image of the Si surface sputtered through the polycarbonate mask. Before recording this AFM image, the polycarbonate layer was peeled off (some residual polymer scraps remained on the Si surface visible as white spots). The sputter process has produced clearly visible cavities. Their oval shape is probably an artifact from the horizontal scanning, because by means of SEM circular-shaped craters were observed (cf. Fig. 4b). The number density of the craters is $5 \times 10^{8} \mathrm{~cm}^{-2}$ which corresponds to the number of pores in the polymer mask. This means that every pore in the polycarbonate film acts as nanometric mask aperture for the sputtering process. Due to the large curvature of the AFM cantilever used, the depth of the craters could not be estimated properly. For this purpose, a sample sputtered with a fluence of $10^{18} \mathrm{Xe} / \mathrm{cm}^{2}$ was fractured and the breaking edge was examined by SEM. As demonstrated in Fig. 4a, the depths of the cavities in the silicon can reach $150 \mathrm{~nm}$. Using the SRIM 2006 code [14], the sputter yield for $5-\mathrm{keV}$ Xe ions is $1.74 \mathrm{Si}$-atoms per ion resulting in a maximum sputter depth of $330 \mathrm{~nm}$. The smaller crater depth observed in Fig. 4a is not understood but could result from redeposited sputtered material. At the Si surface the craters are round and have a mean diameter of $69 \pm 8 \mathrm{~nm}$ (Fig. 4b). The crater diameter in silicon is similar to the pore size in the polycarbonate mask. However, a direct size comparison is 
difficult because the polycarbonate film is modified by the sputtering process. First of all, the uncoated polycarbonate surface did not charge during SEM analysis (acceleration voltage 30 $\mathrm{kV}$ ), probably because the Xe beam induced graphitization of the originally insulating polymer. Second, sputtering seems to enlarge the polycarbonate pores to $48 \pm 6 \mathrm{~nm}$ for $10^{17}$ $\mathrm{Xe} / \mathrm{cm}^{2}$ and to $82 \pm 9 \mathrm{~nm}$ (for $10^{18} \mathrm{Xe} / \mathrm{cm}^{2}$ ).

\section{$\underline{\text { Conclusion }}$}

Thin polycarbonate films spin-coated on silicon substrates were irradiated with 1-GeV U ions. The ion tracks in the polymer layer were chemically etched yielding pores with a diameter of about $40 \mathrm{~nm}$. In a second process, the polymer film containing the nanopores acted as mask for structuring the Si substrate underneath. Sputtering with 5-keV Xe ions produced surface craters of depth $\sim 150 \mathrm{~nm}$ and diameter $\sim 70 \mathrm{~nm}$. The results clearly demonstrate that tracketched nanopores in a thin spin-coated polymer layer can serve as structuring mask for the substrate layer below as e.g. required for the fabrication of nanodevices based on diamondlike carbon. The irradiation fluence determines the crater density, and the pore diameter is adjusted by the track etching process. Nanoporous spin-coated polymer masks also open new opportunities for combining ion-track and silicon technology. This is of particular interest because silicon does not record ion tracks and is thus insensitive to structuring processes with swift heavy ions in the electronic energy loss regime. Further work will focus on the fabrication of a self-aligned field emission device and electrical contacts for graphite-like conductive ion track in ta-C.

\section{Acknowledgements}

We would like to thank Kun Zhang (University of Göttingen) for his assistance with sputtering and AFM measurements. This work was financially supported by the Deutsche Forschungsgemeinschaft (DFG Ho1125/17-1) and the Bundesministerium für Bildung und Forschung (BMBF 05 KK4MGA/9). 


\section{$\underline{\text { References }}$}

[1] R. L. Fleischer, P. B. Price, R. M. Walker: Nuclear tracks in solids. Principles and Applications. University of California Press, Berkeley (1975)

[2] R. Spohr: Ion tracks and microtechnology, principles and applications. Vieweg Verlag, Braunschweig (1990)

[3] M. Toulemonde, C. Trautmann, E. Balanzat, K. Hjort, A. Weidinger, Nucl. Instr. Meth B $216(2004) 1$

[4] P. Apel, Nucl. Instr. Meth. B 208 (2003) 11

[5] D. Dobrev, J. Vetter, N. Angert, R. Neumann, Appl. Phys. A 69 (1999) 233

[6] S. Karim, M.E. Toimil-Molares, F. Maurer, G. Miehe, W. Ensinger, J. Liu, T.W.

Cornelius, R. Neumann, Appl. Phys. A 84 (2006) 403

[7] T. Ohgai, K. Hjort, R. Spohr, R. Neumann, J Appl Electrochem 38 (2008) 713

[8] M. Waiblinger, Ch. Sommerhalter, B. Pietzak, J. Krauser, B. Mertesacker, M. CH. LuxSteiner, S. Klaumünzer, A. Weidinger, C. Ronning, H. Hofsäß, Appl. Phys. A 69 (1999) 239 [9] A.-K. Nix, D. Schwen., C. Ronning, J. Krauser, C. Trautmann, H. Hofsäss, Rev. Adv. Mater. Sci. 15 (2007) 192

[10] J.-H. Zollondz, J. Krauser, A.,Weidinger, C. Trautmann, D. Schwen, C. Ronning, H. Hofsaess, B. Schultrich, Diamond and Related Materials 12 (2003) 938

[11] D. Schwen, C. Ronning, H. Hofsäss, Diamond Relat. Mater. 13 (2004) 1032

[12] T. W. Cornelius, P.Yu. Apel, B. Schiedt, C. Trautmann, M. E. Toimil-Molares, S. Karim, R. Neumann, Nucl. Instr. and Meth. in Phys. Res. B 265 (2007) 553-557

[13] L. Dauginet-De Pra, E. Ferain, R. Legras, S. Demoustier-Champagne, Nucl. Instr. and Meth. in Phys. Res. B 196 (2002) 81

[14] SRIM version 2006.02 available on www.srim.org 


\section{Figures}
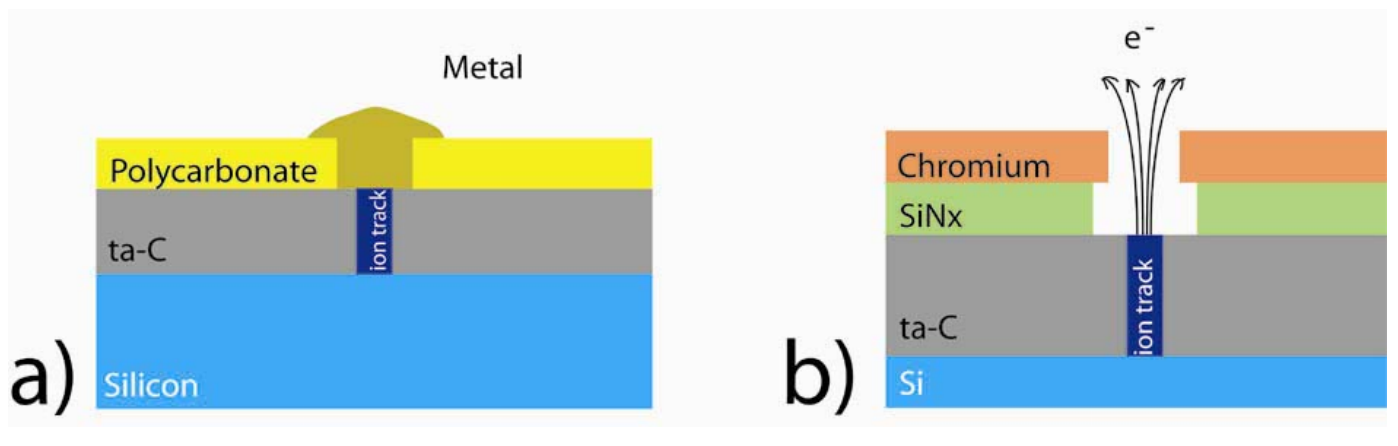

Fig. 1: Scheme of possible nanostructured systems based on chemical etching of ion tracks in polymer films on diamond-like carbon substrate (ta-C) either directly spin-coated (a) or deposited on top of a multilayer system (b). The etched pore can either be filled with metal serving as electrical contact to the conducting track in Ta-C (a) or alternatively represents a self-aligned aperture for a field emission device with built in gate electrode.

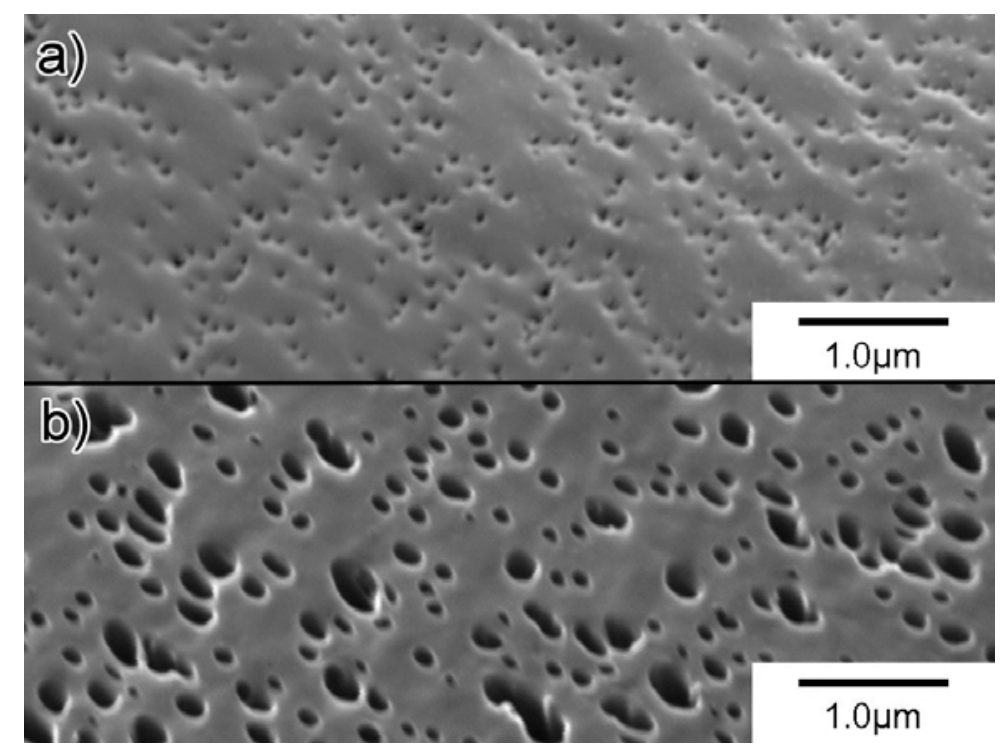

Fig. 2 SEM image of ion-irradiated and track-etched polycarbonate film spin-coated on Si substrate. Chemical etching was performed in $\mathrm{NaOH}(5 \mathrm{M}, \mathrm{RT})$ for about 45 minutes: (a) top and (b) rear side of polymer film. 


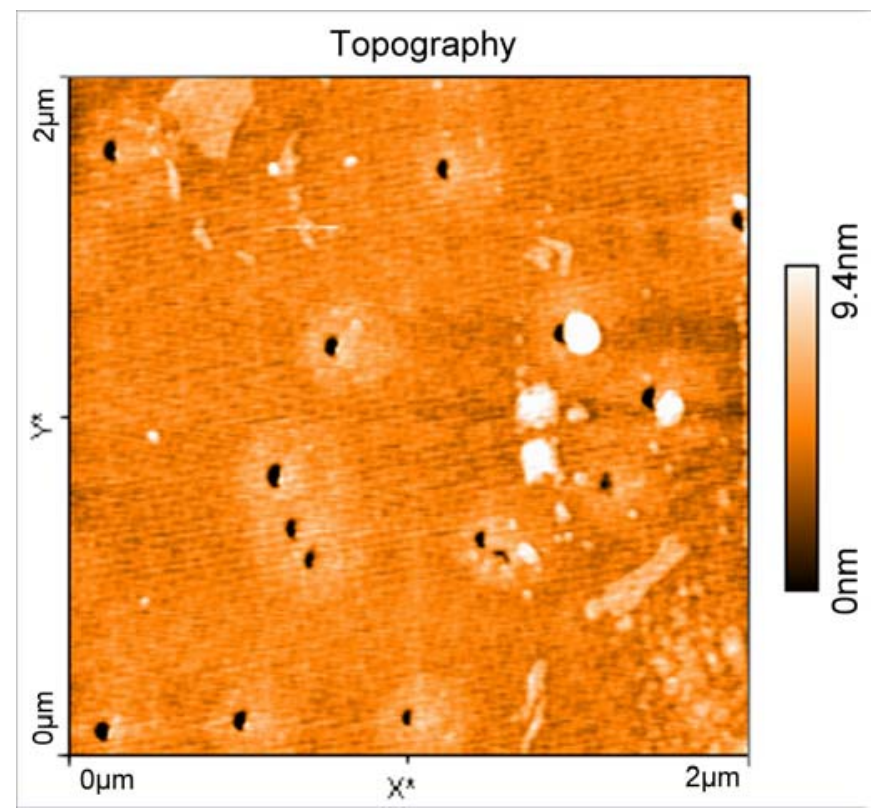

Fig. 3: AFM image of silicon surface after sputtering with $10^{17} \mathrm{Xe}$-ions $/ \mathrm{cm}^{2}$ using the pores $\left(5 \times 10^{8} \mathrm{~cm}^{-2}\right)$ in spin-coated polycarbonate film as mask. For imaging the polymer film was removed.

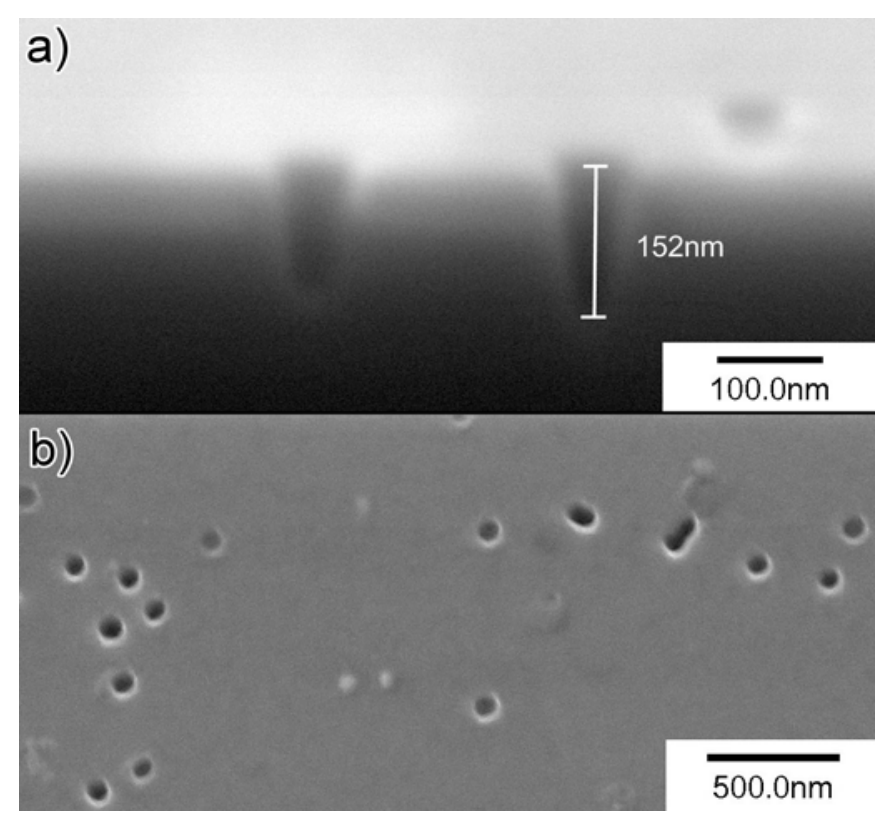

Fig. 4: SEM images of a silicon sample sputtered with $10^{18}$ ions $/ \mathrm{cm}^{2}$ through a polycarbonate mask: (a) cross sectional view: the conical craters reach a depth of about $150 \mathrm{~nm}$ and have an opening angle of $\sim 13^{\circ}$; (b) top view: Circular-shaped surface cavities with $\sim 70 \mathrm{~nm}$ diameter. 